\title{
Pedagogização da INFÂNCIA: REFLETINDO SOBRE PODER E REGULAÇÃO*
}

Aliandra Cristina Mesomo Lira**

\section{RESUMO}

Partindo de um estranhamento diante das práticas educativas com crianças na educação infantil, em que reconhecemos investidas de pedagogização marcadas por prescrições disciplinares e regulatórias, o objetivo deste artigo é problematizar como o poder se exerce nessas práticas por meio de técnicas que tomam o corpo infantil como objeto, ou seja, tentar entender como o poder se apresenta e atua nas mais diversas situações e interações. As reflexões são parte de uma pesquisa que teve como principal fonte observações realizadas em uma instituição pública de educação infantil. Identificamos formas de organizar os espaços e conduzir as práticas com os infantis que revelam e se servem de uma intenção reguladora e disciplinadora dos indivíduos, tanto mais produtiva quanto mais naturalizada.

Palavras-chave: Educação infantil. Poder. Pedagogização. Regulação.

\section{INTRODUÇÃO}

Desafiando-nos a usar "novas lentes" para "ver" os fenômenos educativos na educação infantil (BuJEs, 2002b), este artigo apresenta discussões acerca das relações de poder que permeiam o contexto educacional estruturado para crianças pequenas.

A hipótese de que as formas existentes de organizar e conduzir as práticas com os infantis revelam e se servem de uma intenção reguladora e disciplinadora dos indivíduos direcionou nosso olhar para a instituição

\footnotetext{
* Artigo recebido em 23/06/2008 e aprovado em 17/10/2008.

** Professora do curso de Pedagogia da Universidade Estadual do Centro-Oeste-PR e dutoranda em Educação pela Universidade de São Paulo. E-mail: aliandra@usp.br
} 
investigada, ${ }^{1}$ os seus regimes e as suas relações, procurando observar os mínimos detalhes que atravessam suas múltiplas interações. Nossa pesquisa se propôs a indagar sobre situações de poder em uma instituição de educação infantil do município de São Paulo e problematizar as relações aí presentes. $\mathrm{O}$ intuito foi o de procurar compreender essas relações e buscar seus efeitos possíveis, abrindo possibilidades para pensar alternativas de outros modos de pensar e fazer a educação infantil.

Alves (2002), ao descrever as implicações de uma pesquisa que se propõe a investigar práticas no cotidiano das escolas, reflete sobre suas exigências:

Buscar entender, de maneira diferente do aprendido, as atividades do cotidiano escolar ou do cotidiano comum, exige que esteja disposta a ver além daquilo que outros já viram e muito mais: que seja capaz de mergulhar inteiramente em uma determinada realidade buscando referências de sons, sendo capaz de engolir sentindo a variedade de gostos, caminhar tocando coisas e pessoas e me deixando tocar por elas, cheirando os odores que a realidade coloca a cada ponto do caminho diário. (p. 17)

As alterações das últimas décadas na área da educação infantil, ${ }^{2}$ tanto em termos de leis e documentos como no número de atendimentos e nas discussões por parte de estudiosos e pesquisadores, trouxeram conquistas mas também novas características e novos embates na área e nas próprias práticas.

As formas de ver a infância ao longo da história foram se modificando, sendo que os últimos séculos passaram a colocar a criança no centro das preocupações e discussões, tanto em níveis mais gerais como em termos educativos. Assim, a historiografia nos mostra que o início dos tempos modernos trouxe como focos de preocupação a infância e a sua educação. Nesse sentido, as instituições escolares tornaram-se um meio de disciplinar as crianças por meio de estratégias de vigilância e esquadrinhamento. ${ }^{3}$ A concepção educativa do final do século XVIII e início do século XIX compreendia a necessidade de preparar a criança para a vida adulta, por meio de uma disciplina constante e rigorosa (ARIÈs, 1981), conseguida mais facilmente nas instituições.

Além disso, embora o momento histórico atual esteja marcado por uma maior organização das ações e discussões que incluem novas concepções educacionais de atendimento à infância, a maioria das prá- 
ticas ainda apresenta muitos problemas, resultado de incompreensões e desentendimentos sobre as necessidades das crianças.

\section{FUNDAMENTAÇ̃̃o TEÓRICA, METODOLOGIA E UNIVERSO PESQUISADO}

Pensando sobre as práticas atuais com os infantis, colocou-se como objetivo da pesquisa identificar como o poder se exerce nessas práticas mediante técnicas que tomam o corpo infantil como objeto. Ou seja, tentar reconhecer como o poder se apresenta e atua nas mais diversas situações. A preocupação se justifica na medida em que as características modernas de disciplinarização e controle penetraram em todos os tempos e espaços escolares e determinam as concepções, as experiências e o dia-a-dia nas instituições.

Partindo das idéias de Michel Foucault sobre o poder, a dominação e a disciplinarização dos corpos nas instituições, juntamente com estudos de pesquisadores que seguem essa linha de pensamento, procuramos observar as práticas da instituição investigada buscando desvelar aspectos das relações de poder e suas implicações para os sujeitos infantis.

Inspiramo-nos no caráter regulador e produtor das práticas descrito por Foucault (1987) na análise das instituições disciplinares. As diferentes técnicas são apresentadas pelo filósofo que identifica na minúcia dos regulamentos e no controle dos mínimos detalhes a produção dos sujeitos dóceis e manipuláveis da sociedade moderna. Esses dispositivos disciplinares constituem, pelas tecnologias de poder, um novo indivíduo que passa a se autocontrolar e autogovernar. Essa anatomia política, por meio de seus mecanismos de poder, esquadrinha o corpo humano, observando-o individualmente e desarticulando-o.

Juntamente com o disciplinamento dos corpos, identifica-se o dos saberes (VARELA, 1996), ou seja, o poder disciplinar atua na produção dos sujeitos e na produção dos saberes. Na produção desses saberes, entram em cena, em diferentes épocas, as pedagogias disciplinares (século $\mathrm{XVIII}$ ), as pedagogias corretivas (início do século XX) e as pedagogias psicológicas (em expansão na atualidade):

Três modelos pedagógicos que implicam diferentes concepções do espaço e do tempo, diferentes formas de exercício do poder, diferentes formas de conferir um estatuto ao "saber" e diferentes formas de produção da subjetividade. (p. 78) 
Foucault (1987) nos fala de um poder que produz mais do que reprime e que não se concentra em um indivíduo ou espaço, mas tem uma localização dispersa e difusa, existindo em atos e ações e em todas as circunstâncias. É tomando esse conceito que procuramos identificar como esse poder se exerce e atua na instituição de educação infantil, considerando que mais importante que analisar as práticas é perceber as relações que nelas se estabelecem e, consequentemente, seus efeitos.

Nesse sentido, o presente estudo partiu de uma fundamentação teórica, na qual pensadores como Foucault (1987) e pesquisadores e estudiosos que nele se apóiam entendem a escola como uma instituição social que colabora na constituição de sujeitos adaptados e moldados para conviverem em situações de controle intenso e diário (BUJEs, 2002a, 2000; CoRAzZA, 2002). Além disso, a forte ênfase na pedagogização das práticas que caracteriza a educação infantil nas últimas décadas revela um dia-a-dia impregnado de rituais que priorizam a escrita e o cálculo, acompanhados pelos tradicionais procedimentos pedagógicos, muitas vezes deteriorando inclusive as experiências com o brincar, tão importantes para a infância.

Em face destas questões, fomos percebendo no decorrer da investigação que mais importante do que os resultados foi entrarmos em contato com as relações que se estabeleciam na instituição; as conversas com as professoras e delas com as crianças tiveram significado e atenção especial; e os dados coletados permitiram, ao longo da pesquisa, encontrar o foco central para o estudo. O estudo de caso apresentou-se como uma possibilidade de investigar e compreender os seres humanos e suas ações mais profundamente, especialmente no cotidiano escolar.

A pesquisa foi realizada em uma Escola Municipal de Educação Infantil (Emei) de São Paulo situada na região oeste da cidade. A instituição observada foi fundada no ano de 1943, passando por várias denominações até tornar-se Emei nas últimas décadas. Conta com quatro salas de aula que atendem nos três períodos diários cerca de 450 crianças de 4 a 6 anos. As classes formadas agrupam de 35 a 40 alunos. $O$ corpo docente da instituição é formado por profissionais formados em curso superior, sendo que para as demais funções o quadro funcional encontrava-se completo ao tempo da pesquisa. Quanto às características físicas, a escola conta com quatro salas de aula, uma secretaria, uma biblioteca, uma sala de professores, uma sala de direção, uma sala de informática, uma brinquedoteca, dez sanitários, uma cozinha, dois almoxarifados, 
um refeitório, uma área de serviço, um galpão, estacionamento e parque, totalizando 3.690 metros quadrados.

$\mathrm{O}$ estudo de caso focalizou quatro turmas de $3^{\circ}$ estágio, que atendem crianças de cinco e meio a seis e meio ou sete anos, nos três turnos da escola (das 7 às 11 horas, das 11 às 15 horas e das 15 às 19 horas). ${ }^{4} \mathrm{~A}$ disponibilidade das professoras em aceitar que observássemos a turma foi o critério para a escolha desse estágio.

A definição dos dias e das jornadas de observação foi combinada com as próprias professoras, de modo a não atrapalhar o planejamento anteriormente programado, acontecendo nas diferentes turmas no período de março a setembro de 2003. Foram feitos observações constantes e registros em diário, além de conversas com as professoras.

Depois de um primeiro contato com a turma, da apresentação e do reconhecimento das características gerais do grupo, foi definido um critério importante para as observações: seria acompanhado, do início ao fim do trabalho, o desenvolvimento de uma atividade em cada turma. Por exemplo: confecção de um jogo, livro de literatura e as atividades envolvidas, miniprojetos (parlendas, animais de jardim, família etc.). Dessa forma, direcionamos e orientamos as observações, focalizando o olhar.

Além dos relatos das observações, utilizamos como fontes as falas das professoras nas conversas que aconteceram durante a estada na instituição e também fotos dos ambientes, espaços da escola. ${ }^{5}$ A variedade de fontes permitiu-nos identificar a regularidade e solidariedade dos mecanismos e das técnicas de poder empreendidas na instituição. Ou seja, a continuidade e progressividade das interdições que podem indicar os possíveis efeitos desse poder na constituição dos infantis e indicar que os sujeitos são o produto dessas relações.

O material da investigação foi examinado rigorosa e minuciosamente várias vezes, confrontado com novas possibilidades de relações e procurando alcançar outras, diferentes e novas, formas de inteligibilidade (BuJes, 2002b). A partir do corpo dos elementos, dos dados empíricos, procuramos isolar alguns, estabelecer e reconhecer relações, organizálos em blocos, conjuntos, que permitissem perceber suas repetições e associações. Ou seja, buscamos no material coletado as continuidades, as recorrências que evidenciassem a intensidade e solidariedade das ações. 


\section{ESCOLARIZAÇÃO E PODER}

Como já mencionamos anteriormente, a associação da infância com a escola fez parte do projeto moderno das sociedades, evidenciando práticas que foram se modificando ao longo dos tempos. A era moderna estabeleceu uma nova ordem em que os castigos corporais, generalizados nas práticas disciplinares dos séculos anteriores, foram aos poucos abolidos em nome de uma disciplina mais sutil. Assim, a normatização dos fins da escolaridade é típica da modernidade, com seu ideal escolar homogeinizador na direção de um controle sobre todos os sujeitos e sobre todos os processos (NARODOwSKI, 2001). Técnica e ciência aliadas constituíram os projetos sociais que atenderam aos anseios de setores da sociedade, juntamente com modos de regulação do fazer social (MATE, 2002).

Tais práticas de controle permitiram categorizações e separações, de modo que os séculos XVIII e XIX tornaram-se períodos fundantes da magnitude das relações de poder escolar. Não bastava mais somente punir, agora era preciso "[...] vigiar, corrigir, reeducar, organizando o tempo e o espaço e formulando novas técnicas de vigilância [...]” (SINGER, 1997, p. 41).

A concepção moderna de infância, que coloca a criança como aprendiz (Popkewitz, 2002), introduz um esquema de racionalidade que passa a medir, classificar, avaliar as crianças de acordo com seu desenvolvimento, seu comportamento, sua personalidade. Nesses termos, reconhece-se que a escolarização surge em correspondência à necessidade de governar os indivíduos, introduzindo formas de ser e de estar vinculadas às questões do poder e da regulação.

Numa visão crítica da história da educação (MATE, 2002), a escolarização pode ser vista como um processo de racionalização do tempo dos indivíduos e gradativa disciplinarização de seus corpos, legitimando-se saberes e espaços que são apresentados como partes naturais da escolaridade.

A racionalização do tempo dos indivíduos dentro da instituição escolar nos remete a um longo processo de organização e legitimação de saberes, espaços e materiais relativos ao ensino/aprendizagem, criação de relações pedagógicas impessoais e formais, imposição de tarefas extrínsecas aos interesses de alunos e professores, organização burocrática do tempo e 
horário escolares, hierarquia de funções etc. São formas que resultaram de gradativa disciplinarização dos corpos dentro de espaços e tempos determinados, e que hoje se apresentam como naturais, como parte da escolaridade. (p. 25-26)

Segundo Varela e Alvarez-Uria (1992), as instituições escolares surgiram e se propagaram a partir de uma série de dispositivos de controle da sociedade e da infância, que foram emergindo desde o século XVI quando as crianças passaram a ser alvo de atenções. Foi sendo construída uma "maquinaria de governo da infância" que ocupava o tempo e pretendia imobilizar os espaços. Infância e escola são construções recentes (já que não existiram sempre), resultantes de uma série de condições sociais conjugadas.

A escolarização introduziu uma prática institucional de captura dos sujeitos, utilizando-se de dispositivos pedagógicos que ao mesmo tempo regulam e produzem os indivíduos. Trata-se de um conjunto de operações orientadas para "produzir, capturar e mediar pedagogicamente alguma modalidade da relação da pessoa consigo mesma, com o objetivo explícito de sua transformação [...]" (LARRosa, 2002, p. 51).

Ao descrever as formas modernas de fabricação do sujeito e seus esquemas, Foucault (1987) identifica, já no século XVIII, as técnicas disciplinares que posteriormente se refinam e especializam-se, tornando-se mais sutis. $\mathrm{O}$ autor encontra nos hospitais, nas fábricas, no exército, nas prisões, nas escolas, semelhanças entre as formas de sujeição e as formas de produção de gestos e de indivíduos eficientes. A preocupação com o controle dos corpos, com o adestramento e com a correção aparecia em todos os espaços, estabelecendo um "elo coercitivo entre uma aptidão aumentada e uma dominação acentuada" (p. 119).

O filósofo descreve a disciplina como a arte das distribuições nos tempos e espaços que cerceia liberdades, conforma atitudes e normaliza. O esquadrinhamento nas instituições, dentre elas a escola, separa os indivíduos nos espaços, sendo importante "saber onde e como encontrar os indivíduos, instaurar as comunicações úteis, interromper as outras, poder a cada instante vigiar o comportamento de cada um, apreciá-lo, sancioná-lo, medir as qualidades ou os méritos. Procedimento, portanto, para conhecer, dominar e utilizar. A disciplina organiza um espaço analítico" (FoUCAULT, 1987, p. 123). 
A disciplina como recurso para o adestramento não tem o intuito de reduzir as forças, mas sim juntá-las para multiplicar e produzir. Ela funciona permanentemente, utilizando além da punição, como sanção para normalizar, o olhar e o exame.

Em um estudo específico de educação infantil, a escolarização é apresentada como introdução de leitura, escrita e cálculo por meio de procedimentos inadequados sem valorizar as experiências infantis numa "[...] concepção de educação infantil que privilegia a reprodução da escrita em detrimento de atividades que focalizam experiências em jogos, artes, ciências, linguagem, livros infantis entre outros" (Кізнімото, 2001, p. 240). Uma inadequação de práticas que privilegiam a leitura, a escrita e o cálculo, desrespeitando a aquisição de experiências com sentido pela criança e desvalorizando a representação simbólica e o brincar.

Segundo a autora, são raras as propostas, desde a implantação dos primeiros jardins de infância, preocupadas com a socialização e as experiências das crianças. $\mathrm{O}$ que se percebe é que as experiências se dividem entre as que reproduzem a escola elementar (escolarização) e as que valorizam a socialização e as vivências infantis.

Pesquisas realizadas na última década apontam o privilégio, nas instituições, de materiais gráficos e educativos, evidenciando uma predominância de preocupações com o modelo escolar e consequentemente marginalizando a expressão criativa e a iniciativa das crianças (КISнIмOTO, 1998). Privilegia-se uma gerência sobre a vida das crianças que permite maior controle e produtividade e uma educação infantil predominantemente "conteudista".

Para Bujes (2002a), o objetivo da maioria das práticas na educação infantil, que adotam modelos escolarizantes e repetitivos, é obter respostas padronizadas e automáticas, uma homogeneidade não conseguida em atividades livres e, portanto, menos controláveis. Essa vigilância constante que acontece na educação infantil, conseguida pela distribuição espacial programada que reparte, separa, divide, é produtiva e instaura relações de poder:

Através da vigilância que esta observação constante produz, as crianças, objetos de controle, são conhecidas em seus modos de agir, de conduzir-se, em suas preferências, em suas "esquisitices". Seus traços mais característicos são identificados, ganhando, deste modo, cada uma, um caráter individualizado. (p. 125) 
Todos esses aspectos da escolarização com seus instrumentos disciplinares apontam para a grande questão da modernidade, que foi a de inventar meios para tornar os indivíduos e a sociedade administráveis. Nesse sentido, a instituição escolar, mediante diversas técnicas, constituiu-se e constitui-se como um dos principais lugares onde essa administração e produção acontecem.

\section{EDUCANDO PARA GOVERNAR: CORPOS, TEMPOS E ESPAÇOS}

A articulação dos poderes na sociedade moderna permitiu a produção e aplicação de uma série de instrumentos e táticas sobre os corpos. A arte de direcionar a conduta, de agir sobre a ação do outro, aparece nas práticas, nos tempos e nos espaços das instituições escolares, produzindo um indivíduo cada vez mais governado e auto-regulado. $\mathrm{O}$ "governamento", segundo Bujes (2002a), significa os modos como é exercido e como se exerce o poder, no sentido de organizar, administrar a conduta do outro de modo que adquira o autogoverno. O termo aparece em Michel Foucault (2003) com a expressão "governamentalidade", ou seja, o conjunto de instituições que possibilitem as práticas de governamento.

Foucault (2003) discute a questão do governo diferenciando-o de aparelho estatal, pois o apresenta como um governo das idéias e dos seres humanos em suas relações. Assim, o governamento que se desenvolveu a partir do início da modernidade passa a gerir em profundidade, minuciosamente e no detalhe, atentando para a correta disposição dos objetos e das idéias e conduzindo os indivíduos para um fim conveniente e específico, conseguido por meio de uma série de estratégias. Mediante variados meios e em diferentes lugares (principalmente institucionais), faz-se com que determinados fins sejam atingidos, intensificando-se os processos e diversificando-se os instrumentos.

Em nossa pesquisa, foi possível observar como as práticas adotadas têm um papel de produção dos indivíduos, como os espaços potencializam essa produção e como os discursos e as concepções dos adultos orientam as escolhas nas instituições e estão coerentes com a produção de determinadas subjetividades, de determinados sujeitos. Ou seja, os processos, as opções são fabricados nas relações de poder que se estabelecem.

Partindo da compreensão foucaultiana de que não existe posição de exterioridade em relação ao poder devido à localização dispersa e difusa que o coloca em todas as ações, circunstâncias e espaços, procuramos 
identificar como esse poder se exerce na educação infantil. Tal análise parte das práticas, mas mais importante que elas são as relações que se estabelecem, as intencionalidades das escolhas e também seus efeitos.

A observação feita sobre as práticas e a análise dos documentos e dos discursos institucionais apresentam alguns indícios que indicam o porquê e principalmente o como de determinadas escolhas. São essas lógicas e relações de poder, algumas vezes implícitas outras vezes não, presentes nas práticas e no privilégio de determinadas atividades pedagógicas, que nos propomos a analisar e problematizar.

Com base na descrição do processo de disciplinarização feita por Foucault (1987), reconhecemos que o poder disciplinar toma o corpo dos indivíduos de duas formas bem específicas que se conjugam e se interligam: a separação dos corpos nos espaços e a sujeição dos corpos ao tempo. As separações dos corpos no espaço e as durações temporais a que estão sujeitos os indivíduos constituem-se como uma função essencial do poder disciplinar.

Nas escolas, os indivíduos não fazem qualquer coisa, em qualquer momento, em qualquer lugar. Os espaços são cuidadosamente delimitados, o tempo é marcado por um cronograma preciso, regular e regulado, os aprendizados são organizados em etapas, de forma tal a exercitar, em cada período, um tipo de habilidade específica. (KoHan, 2003, p. 79)

Ao organizar o tempo em séries múltiplas e progressivas, a disciplina manipula-o, estabelecendo momentos integrados e orientados para o máximo de rendimento. Narodowski e Van der Horst (1999) mencionam que o tempo escolar e seu uso aparecem pautados e controlados: horários de entrada e saída, recreios, brincadeiras, atividades. Como bem assinalam os autores, o não-cumprimento desses horários implica, geralmente, em algum tipo de observação que evidencia as ações "negativas" e as condena.

Na sujeição dos indivíduos ao tempo, todos os gestos e atos estão atrelados aos controles temporais, com vistas ao máximo de rapidez e eficácia. Esse controle do tempo penetra os corpos, anulando tudo o que possa distrair, o que leva a sua internalização e a um ordenamento produtivo. Vejamos como isso aparece nas observações feitas para nossa investigação: 
Turma 1, professora A, 19/02/03

Da turma de 38 alunos há apenas 11 porque o transporte escolar da prefeitura está em greve. A professora explica que isso acontece porque as crianças dependem do transporte para vir à escola. Não sou apresentada à turma.

Quando chego, os alunos estão ao redor de uma das mesas da sala (redondas, de aproximadamente dois metros de diâmetro), observando a professora e mais três crianças jogarem um joguinho, novo para eles. A professora vai jogando e reforçando as explicações. Isso dura mais ou menos uma hora. Alguns observam e outros estão um pouco dispersos. Depois termina o tempo de jogar e é hora de lanchar.

Hora do lanche. As crianças vão até o refeitório, acompanhados pela professora que orienta para não correr, não gritar, dentre outras recomendações que acredito serem diárias.

Quando voltam para a sala, os alunos sentam às mesas em seus lugares e a professora começa uma conversa sobre a dengue, reforçando a campanha municipal e nacional de combate à epidemia. A professora mostra folhetos, dá informações e algumas crianças colaboram com falas relativas ao dia-a-dia. Ela me informa que já havia falado sobre o assunto na semana anterior.

Depois da conversa, os alunos fazem a escovação dos dentes, pois antes outra turma estava usando os banheiros. A professora reforça as normas que, segundo ela, já tinham sido explicadas. A conversa acontece em forma de perguntas: "Pode derrubar água?" Os alunos respondem: "Não"; "Pode molhar a roupa?"; "Não"; e outras.

Depois da escovação, quando todos já estão na sala, a professora pergunta aos alunos o que eles preferem: fazer um desenho livre ou brincar com os joguinhos. As crianças preferem jogar e a professora distribui um jogo para cada mesa. As crianças organizam-se, mas não muito empolgadas.

Por estarem poucos alunos presentes, a professora afirma que organizou a aula com conversa e brincadeiras para que os alunos que faltaram não perdessem atividades.

Depois, as crianças vão para o parque, onde ficam por uns 40 minutos. Enquanto correm, brincam etc., a professora fica sentada observando e atendendo a algumas crianças.

Temporalmente, as crianças vão passando de uma atividade a outra, o que evidencia uma segmentação do tempo que se apresenta como necessária e natural. As atividades decompostas e a passagem de uma para a outra é um processo que acontece maquinalmente, no sentido 
de um uso eficaz do tempo que segue uma sucessividade. Cada criança deve terminar a atividade de cada tempo para que todos possam passar para o outro momento.

Uma exigência básica para que esse mecanismo (encadeamento temporal) funcione é que a atividade prevista para cada segmento temporal colocado em série seja efetuada. Nada deve ficar incompleto, de maneira que a continuidade de qualquer realização ligada a uma duração seja a garantia de que todos os seus componentes que ficaram para trás tenham sido rigorosamente cumpridos. (FonSECA, 2003, p. 67)

Para Bujes (2002a), o poder manipula o tempo e o corpo, buscando eficiência: o tempo de cada um deve ajustar-se ao tempo dos outros, sendo o ritmo individual imposto a partir do exterior. Com séries múltiplas e progressivas, constitui-se o tempo disciplinar, que tem estabelecido também seus modos de utilização - aproveitamento integral e nada de desvios -, seguindo-se uma atividade a outra.

Turma 1, professora A, 12/03/03

Guardados os jogos, a professora vai à lousa e fala: "Agora vamos continuar com a aulinha de matemática". Conta as letras do alfabeto, primeiro sozinha e depois os alunos repetem; conta os alunos da sala. Depois, ao contar as vogais de uma palavra, diz que agora estão aprendendo português. Depois as crianças lancham e vão para o parque.

As ocupações determinadas nos tempos regulamentam repetições em que as divisões tornam-se cada vez mais esmiuçantes. A divisão em tempos de aprender, de comer, de brincar, de cuidar do corpo, por exemplo, impõe uma regularidade e uma regulação ininterruptas.

A distribuição espacial ajuda no controle dos comportamentos e o uso determinado dos espaços e lugares se apresenta como estratégico e fundamental a esse mecanismo disciplinar. A estabilidade é estimulada e vigiada constantemente nos espaços.

O espaço deve ser, para o procedimento disciplinar, um meio de distribuição que permita a análise e a utilização particular e combinatória dos indivíduos. Com esse objetivo é desenvolvida uma arte das distribuições, marcada pela precisão das posições. Se houvesse um procedimento totalmente incompatível com a economia da disciplina, ele seria a distribuição 
aleatória dos indivíduos no espaço ou, melhor ainda, a desatenção para com o problema do espaço. (FonseCA, 2003, p. 63)

Turma 2, professora B, 07/08/03

No almoço, as crianças não se servem nem pegam os talheres e a professora inclusive escolhe os lugares onde eles devem sentar. Algumas crianças não podem sentar perto das outras. A professora fala para um menino: "Não, você não senta perto dele (aponta para outro menino) porque eu já sei o que acontece". Para algumas meninas: "Bom, vocês podem sentar juntas". Algumas crianças olham e ela completa: "Elas se comportam".

A localização exata facilita a vigilância constante que observa todas as ações e reações e aplica sanções sobre os desvios. Além de permitir a observação, deve constituir-se em um espaço útil e rentável em termos de ocupação, facilitando e fomentando a funcionalidade. Segundo Narodowski e Van der Horst (1999), a organização dos espaços oferece um ambiente controlado que permite aos adultos disporem adequadamente das crianças, em vista de um controle interno articulado e detalhado que faz e torna visível quem está dentro da instituição. Logo, não se trata apenas de vigilância e rompimento de comunicações perigosas, mas do estabelecimento, da criação de um espaço útil. A busca por essa utilidade também estabelece uma organização especial das atividades escolares.

A delimitação específica dos espaços garantirá um desenvolvimento ordenado e prescrito das ações educativas, dado o desejo de ordem nas aprendizagens. Desta forma, a forte estruturação e caracterização dos espaços e a permanência neles por períodos prolongados apresentam-nos como um recurso educativo, explorado pelo adulto para realizar uma gerência direta e centralizada da situação. A disposição dos móveis (predomínio de mesas e cadeiras) e dos materiais (guardados em grandes armários) tende a comunicar as possibilidades de ação e as formas de sua realização.

$\mathrm{Na}$ instituição escolar, a norma dita o que é um comportamento aceitável, e os castigos servem para punir os desviantes. Segundo Foucault (1995), uma relação de poder se articula sobre dois elementos indispensáveis: “que 'o outro' (aquele sobre o qual ela se exerce) seja inteiramente reconhecido e mantido até o fim como sujeito de ação; e 
que se abra, diante da relação de poder, todo um campo de respostas, reações, efeitos, invenções possíveis" (p. 243).

Turma 1, professora A, 14/05/03

33 crianças na sala, junto com a coordenadora (a professora ainda não chegou), estão fazendo um "Desenho das brincadeiras".

A professora chega e diz que está com problemas pessoais, que tinha ficado de licença por uns dias. Enquanto isso, as crianças estão desenhando e a coordenadora já saiu da sala. Duas crianças começam a discutir e uma delas risca o desenho da outra, por algum motivo. A professora interrompe a conversa comigo, vai até a mesa, pega uma das crianças pelo braço com força e a leva para a frente da sala. Todas as crianças observam assustadas e a professora fala com a criança, gritando: "Por que você fez isso? Você não era assim! Você não era mal-educado! Vou ter que falar com teu pai". A professora fica repetindo isso e gritando no rosto da criança que tenta falar, mas não consegue e começa a chorar. Esta é colocada de castigo em um canto da sala e fica chorando.

A professora volta à mesa, pega a outra criança e tem a mesma atitude, colocando-a no outro canto da sala. As duas crianças choram isoladas, frente aos olhares assustados das outras crianças.

Rose (2001) assinala que dispositivos de visualização e sistemas de julgamento são produzidos, inventados, refinados e estabilizados para serem disseminados e implantados de diferentes formas nas diferentes práticas e que diferentes ações sobre as pessoas se potencializam e têm a finalidade de normalizar.

À semelhança dos outros níveis de ensino, também na educação infantil empreende-se um sistema de classificações e diferenciações. As crianças são diferenciadas por seu comportamento, por suas experiências, por sua maneira de estar em sala, de brincar, formando-se o que se poderia chamar de categorias, sendo algumas modelares (no sentido de modelo a seguir) e outras muito mais desconfortáveis. Dissemina-se assim uma produtividade que se baseia em detalhes e com seus estigmas penetra os corpos e produz uma autoconsciência, carregada pelos pequenos.

A qualificação dos comportamentos aparece em diversas situações nas instituições. Por meio de questionamentos, de leituras moralizantes, de indicações de ações possíveis e desejáveis. Os comportamentos permitidos ou as repreensões são enfatizados o tempo todo. 
Turma 1, professora A, 26/02/03

Trinta alunos sentados no chão perto da professora que, sentada em uma cadeira, lê uma estória, mostrando as gravuras do livro E eu com isso? (o livro fala sobre o respeito). Poucas vezes a professora se reporta ao livro e, a cada página, interrompe a leitura com comentários demorados que enfatizam comportamentos, "dentro das regras" da escola e da turma. Segundo a professora, ser educado é não brincar no refeitório, não correr, não fazer bagunça etc. A professora vai perguntando, por exemplo: "Pode fazer barulho?"; e as crianças respondem em coro sim ou não. "O que pode fazer? O que é feio fazer? Que comportamentos dos colegas podem ser considerados feios?"

A atividade de contar a estória é demorada e em uma hora a professora leu a metade do livro, que era muito pequeno.

Turma 1, professora A, 19/02/03

Depois da conversa, os alunos fazem a escovação dos dentes, pois antes outra turma estava usando os banheiros. A professora reforça as normas que, segundo ela, já tinham sido explicadas. A conversa acontece em forma de perguntas: "Pode derrubar água?" Os alunos respondem: "Não"; "Pode molhar a roupa?"; " Não"; e outras.

A preocupação com os comportamentos aparece basicamente por meio de controles que acontecem em todos os tempos e espaços. Por meio de variadas técnicas, as crianças são cercadas por todos os lados e realizam atos mecânicos muitas vezes sem pensar ou saber o porquê. As falas do adulto, seu emprego em relação ao grupo e às situações, as formas de seu envolvimento, mesmo quando parecem em uma primeira leitura, vão determinar diretamente a estrutura e o êxito de um encontro, têm extrema importância em relação aos comportamentos infantis e às aprendizagens sociais que, mediante modalidades mais ou menos explícitas de sanções e legitimações, são incentivados e promovidos.

Várias penalidades às crianças são verificadas quando estas desobedecem $a \mathrm{o}$ adulto: quando não andam em fila, quando não sentam onde lhes é determinado, quando conversam, quando, supostamente, desafiam a professora ao fazerem de conta que não a estão ouvindo. Todas essas atitudes não fogem ao olhar atento do professor, sendo consideradas incorretas e punidas verbalmente ou com castigos leves como, por exemplo, ficar na sala no horário do intervalo. 
A função de vigilância é exercida ininterruptamente pelo adulto sobre as crianças através de olhares, falas e atividades. Reconhece-se também na educação infantil, à semelhança de outros níveis de ensino, um sistema de privilégios e sanções. As instituições pré-escolares "estabelecem micropunições relacionadas com o modo como o tempo é utilizado, com as formas como as crianças falam, com seu jeito de usar o corpo e expressar a sua sexualidade, com a maneira de conduzir-se em relação aos outros, etc.” (BuJEs, 2002a, p. 126). Tem-se com isso inúmeras atitudes que não são permitidas como conversar durante as tarefas, parar de fazer as atividades ou recusar-se a fazê-las, desobedecer à professora, não fazer as atividades do jeito que é certo, cantarolar durante a aula, rir etc. Se isso acontecer, são utilizadas uma série de punições que geralmente caracterizam-se por "leves privações e pequenas humilhações" (p. 127), como exposto acima.

A repetição de tarefas e rotinas sem uma compreensão real da sua necessidade demonstra que o que está sendo feito é destituído de sentido para as crianças. As regulações e os castigos para os desatentos e para os que não fazem as atividades também aparecem.

\section{Turma 2, professora B, 14/08/03}

33 alunos na sala. Durante as rotinas diárias, a professora vai repetindo músicas que pedem silêncio ou que falam de comportamentos.

Enquanto vai conversando com algumas crianças sobre tarefas atrasadas, propõe a brincadeira de "cobrinha colorida" em que uma criança fica com uma cobrinha de mentira, procurando nas meias das outras crianças uma cor solicitada pela professora. Ao encontrar a cor na meia de algum colega, entrega a cobrinha para ele e a brincadeira continua. Depois do almoço, as crianças brincam no pátio. Duas crianças de cada vez vão correndo como saci, ganhando aquela que chega primeiro, um jogo competitivo. A professora comenta que trabalha bastante a competição entre os alunos, pois fora da escola, "na vida", também é assim. Fazem mais algumas brincadeiras com o comando da professora e depois brincam na areia com brinquedos. Quem não tinha feito as tarefas do final de semana fica na sala fazendo.

Os vários momentos observados revelaram como as atividades de rotina ocupam grande parte do tempo e caracterizam-se substancialmente com sentido repetitivo. Essas situações apresentam uma fisionomia que evidencia um esquema do tipo ritual de introdução das crianças ao 
cotidiano da instituição. O ritualismo das atividades ativa expectativas de comportamentos que se generalizam mesmo em situações em que as crianças não estão sobre controle direto do adulto.

As rotinas regram e normalizam o dia-a-dia na educação infantil, com práticas previamente pensadas e programadas para ordenar o cotidiano e eliminar as transgressões, o que acaba por eliminar parte do desejo e da felicidade das crianças. Com atividades mecânicas e repetitivas, tarefas são "feitas como que por hábito - uma série de operações executadas maquinalmente por gestos, ritos, códigos, ritmos, costumes [...]" (BARbosa, 2000, p. 96).

Em um estudo sobre as rotinização da infância, Barbosa (2000) aponta as rotinas como um processo de racionalização e tecnologias utilizadas pelos seres humanos e pelas instituições para organizar e controlar a vida, integrando-se ao cotidiano: ${ }^{6}$

A rotina pode tornar-se uma tecnologia de dominação quando não considera o ritmo, a participação, a relação com o mundo, a realização, a fruição, a liberdade, a consciência, a imaginação e as diversas formas de sociabilidade dos sujeitos nela envolvidos. Quando se torna apenas uma sucessão de eventos, de pequenas ações prescritas de maneira precisa, levando as pessoas a agirem e a repetirem gestos e atos em uma sequência de procedimentos que não lhes pertence nem está sob seu domínio, é o vivido sem sentido, pois está cristalizado em absolutos. (p. 96)

Kohan (2003) chama a atenção para o fato de o professor também ser submetido ao poder, estar em relação de dependência e ter exercitada sua consciência, mas que ocupa, ao mesmo tempo, uma posição estratégica na disseminação do poder disciplinar na escola, principalmente porque tal posição é naturalizada e considerada como essencial.

Embora assuma modalidades leves e participativas, entre o professor e a turma há uma relação de submissão absoluta: sem o professor os alunos não saberiam o que fazer, como aprender, de qual maneira comportarse; eles não saberiam o que está bem e o que está mal, como julgar a atitude de um colega, a falta de esforço de si mesmos para cumprir uma tarefa. (p. 88)

Muitas vezes, a presença silenciosa da professora garante o desenvolvimento normal da atividade e visa à estabilidade dos comportamentos. 
Turma 2, professora B, 07/08/03

Antes de entrar para a sala, as crianças ficam sentadas no pátio junto com as outras turmas e cantam músicas acompanhando $\mathrm{CD}$ e fazendo gestos. Estão presentes 30 crianças. Elas ficam em fila e repetem gestos já recorrentes a elas, já que fazem isso todos os dias. Quem não canta, movimenta-se demais ou conversa é chamado a atenção pela professora que está à frente.

Podemos perceber isso na utilização de músicas, que são sempre bem-vindas no dia-a-dia infantil. Porém, cantar sentado e de costas para os colegas, em uma posição quase imóvel, possibilita para a professora um controle de todos e uma visão geral do grupo. Nessa direção, Rocha (2000) aponta que a disciplina obtém efeitos de utilidade: "O olhar disciplinado está sempre atento, olhando para cima, para baixo, intervindo continuamente, é perseverante, consequente, quotidiano e sistemático. É, acima de tudo, vigilante" (p. 190). O exercício do poder inscreve uma rede de observação permanente que violenta, disciplina, regula.

Em outros momentos e espaços, como o refeitório, o governo das interações - de particular interesse do adulto - se traduz em falas de regulação das condutas dos infantis, que constituem dispositivos de marcas das normas institucionais. Dizem respeito, em geral, a hábitos de organização, lugares apropriados, normas de respeito. Tais falas, quando elogiosas, também esclarecem para os alunos as regras permitidas.

Turma 2, professora B, 07/08/03

No almoço, as crianças não se servem nem pegam os talheres e a professora inclusive escolhe os lugares onde elas devem sentar. Algumas crianças não podem sentar perto das outras. A professora fala para um menino: "Não, você não senta perto dele (aponta para outro menino) porque eu já sei o que acontece". Para algumas meninas: "Bom, vocês podem sentar juntas". Algumas crianças olham e ela completa: "Elas se comportam".

Outro aspecto que chamou nossa atenção foram os momentos de brincadeira observados. Foi possível identificar que o caráter lúdico de algumas situações e atividades não as isenta das relações de poder. $\mathrm{Ou}$ seja, não existe situação, de brincar ou não, que não esteja visceralmente comprometida com o poder. Quando definimos/escolhemos brinquedos, quando vigiamos as práticas, quando as controlamos e dirigimos, o brinquedo, as brincadeiras, os jogos estão permeados pelo poder. 
Turma 1, professora A, 19/02/03

Quando chego, os alunos estão ao redor de uma das mesas da sala (redondas, de aproximadamente dois metros de diâmetro), observando a professora e mais três crianças jogarem um joguinho, novo para eles. A professora vai jogando e reforçando as explicações. Isso dura mais ou menos uma hora. Alguns observam e outros estão um pouco dispersos. Depois termina o tempo de jogar e é hora de lanchar.

\section{Turma 2, professora B, 27/08/03}

Ao terminarem a observação, vão brincar no tanque de areia sob o olhar da professora sentada diante deles. Quando alguma coisa ou comportamento desagrada, as crianças são repreendidas e algumas são proibidas de brincar, devendo ficar sentadas ao lado da professora.

A diretividade verificada no brincar aparece também fortemente nos momentos de atividades em sala de aula. A preocupação com a escolarização põe em marcha uma organização e separação de conteúdos e um privilégio por atividades escritas.

\section{Turma 4, professora $\mathrm{D}, 16 / 09 / 03$}

Há 33 crianças na sala. Recebem uma folha fotocopiada em que devem escrever nome e data. Há palavras de uma parlenda já trabalhada escritas, misturadas com símbolos. As crianças devem identificar quais são as letras, separá-las dos símbolos e montar as palavras. Depois, leem as palavras e devem desenhar ao lado. Quando terminam, guardam a atividade em suas pastas.

\section{Turma 4, professora D, 19/09/03}

A professora separa as 33 crianças em duplas nas mesas e distribui uma parlenda com algumas frases, faltando serem completadas as outras. Cada dupla recebe uma folha, e a professora, ao distribuir, determina qual das duas crianças vai escrever. São frases para completar intercaladas. As duplas usam um alfabeto para identificar as letras e tentar escrever as frases.

A maior preocupação é com a aquisição de habilidades de leitura e as formas utilizadas para que isso aconteça. Em geral, são atividades de completar, seguir o modelo etc. A criança pequena vira aluno desde cedo e uma série de técnicas, instrumentos e procedimentos são empregados para exercer poder. É a disposição dos objetos e dos meios que põe 
em ação estratégias que levam a alcançar certos fins, em um processo em que a criança reflete sobre si mesma e suas ações para inserir-se no mundo. A identidade pessoal insere-se em um projeto reflexivo de autoconstrução e é objeto de toda uma variedade de esquemas, em certa parte racionalizados.

O que deve ser ressaltado é que o conjunto de práticas, de rotinas e de rituais institucionais, quando orientados por alguns princípios ou metas e balizado por um processo de reflexão, torna tais atividades governamentais como nos explicou Foucault, pois os conecta com vários procedimentos e aparatos cuja finalidade é a de garantir que elas obtenham certos efeitos [...]. (BUJES, 2002a, p. 79)

Segundo a autora, ao procurar reverter o caráter assistencialista, a educação infantil abarcou a qualificação de escolar em seu sentido mais perverso, privilegiando a perspectiva cognitivista que enfatiza a necessidade de conhecer, crescer. Essas práticas pedagógicas são reforçadas por documentos que sugerem diretividades e fragmentações.

A regulação instaura relações que se estabelecem no sentido de ressaltar e prescrever o que deve ser feito e como deve ser feito, situações que conformam, estabelecem, moldam. As diretividades governam a infância e suas experiências.

Turma 1, professora A, 19/03/03

As crianças recebem uma folha em que está escrito "A família" e devem desenhar. A professora ordena: "Desenhar com lápis preto e pintar com lápis de cor".

Turma 2, professora B, 27/08/03

Depois na sala, recebem uma folha com as palavras joaninha, formiga, tatu-bola e devem desenhar a quantidade pedida e copiar a palavra embaixo. A professora fala e mostra como desenhar: "Uma barriguinha, duas asinhas, uma cabecinha e duas anteninhas, assim oh. Todas as joaninhas são assim!!" Faz isso com todos os bichos. As crianças que conversam são chamadas para ficar à frente da lousa, de castigo.

Depois devem fazer outra atividade. Em um sulfite, vão desenhar o filme Vida de inseto. Recebem uma formiga grande recortada num papel amarelo! Devem completar o desenho. 
Instaura-se um autocontrole e uma autoaceitação às atividades e ordens. Ficar sentado e quieto, desenhar com um determinado lápis e não com outro, brincar com determinados brinquedos e não com outros aparece como natural e necessário para o controle e a manutenção da ordem, que propicia um ambiente adequado para a aprendizagem. A todo tempo, em todos os espaços e sobre todos os corpos opera-se um ordenamento produtivo em que "a ordem não tem que ser explicada, nem mesmo formulada; é necessário e suficiente que provoque o comportamento desejado" (Foucault, 1987, p. 140).

Prevalecem práticas divisórias que se justificam como na direção de uma maior autonomia por parte das crianças. Contudo, maior autonomia pode implicar maior governo e maior regulação (SILVA, 1998). Estabelecem-se modos de ação que atuam sobre as potencialidades, sobre as sensibilidades, capacitando os indivíduos a serem autônomos e produtivos (PopKewitz, 1998).

As experiências de si que os indivíduos têm na escola modificam a relação que eles têm consigo mesmos numa direção muito precisa, o que representa as implicações do exercício do poder na constituição da subjetividade. Um poder que, segundo Fischer (1999), implica não só conhecer-se, mas governar-se, aplicar ações a si próprio.

\section{CONSIDERAÇÕES FINAIS}

O contexto atual e suas preocupações educacionais justificam o interesse pela reflexão e investigação das práticas educativas com a infância. $\mathrm{O}$ debate e as discussões das últimas décadas acerca da importância da educação infantil e do respeito aos direitos da criança, em consonância com a elaboração e aprovação de leis e documentos que garantem tais conquistas, trouxe muitos avanços em termos teóricos e discursivos que, no entanto, não foram acompanhados por práticas mais significativas com as crianças.

Diante destas questões, reconhecemos como as formas de pensar e classificar as práticas e os fenômenos são tanto mais produtivas quanto mais naturalizadas, pois ocultam as operações de poder que as construíram como tal. Essas verdades acabadas e calcadas em oposições e classificações têm efeitos normalizadores e excludentes que nos impossibilitam, por exemplo, pensar e reconhecer a história dos atendimentos da infância como uma história de poder. Ou seja, de perceber como na 
base da idéia de infância, de seu comportamento e de seu atendimento entrelaçam-se dinâmicas de poder que conformam e naturalizam práticas e funcionamentos.

Na descrição e problematização dos dados identificamos a pedagogização da maioria das práticas na educação infantil que são permeadas pelo exercício do poder. A atenção sobre as ações foi no sentido de procurar entendê-las em sua intencionalidade, o que permitiu reconhecer que a educação toma para si como principal tarefa a condução da infância. Vale ressaltar que a problematização das relações de poder na escola foi uma tarefa difícil, pois elas são majoritariamente naturalizadas, o que lhes confere uma eficácia muito maior.

Neste sentido, nossa reflexão procurou apontar algumas provisoriedades e quem sabe abrir caminhos para outros trabalhos que não busquem verdades absolutas. Como sabiamente ponderou Veiga-Neto (2003) sobre a incoerência de buscar soluções em seu texto, nossas reflexões também se inscrevem nessas tentativas de ressoar e fulgurar possibilidades de ações:

A desnaturalização dos fenômenos sociais - ou seja, tomá-los não como algo desde sempre dado, mas como algo historicamente construído - é um primeiro e necessário passo para intervir nesses fenômenos. Saber como chegamos a ser o que somos é condição absolutamente necessária, ainda que insuficiente, para resistir, para desarmar, reverter, subverter o que somos e o que fazemos. (p. 7)

Assim, com base nas problematizações aqui apresentadas, assinalamos que a transformação das relações com as crianças e a promoção de práticas mais humanas impõem-se como necessidades imperiosas para a concretização de uma educação menos "governamentalizante". Dissipar os esforços excessivos exigidos das crianças e eliminar as condições desfavoráveis que as capturam e o desrespeito que lhes é infligido são condições para que a infância feliz passe do mito à realidade.

\section{ABSTRACT:}

Starting from an unease about certain educational practices used in children's education, where traces of pedagogization characterized by disciplinary and regulatory prescriptions have been recognized, this article aims to analyze how power is exercised in these practices through techniques which consider 
the child's body as an object. In other words, it tries to understand how power presents itself and works within the most diverse situations and interactions. These reflections are part of a research based on observations made at a public institute for children's education. Ways of organizing space and carrying out these practices with the children were identified. They are used with a regulatory and disciplinary purpose on people and are all the more productive, the more naturalized they are.

Key words: Children's education. Power. Pedagogization. Regulation.

\section{NOTAS}

1. Este texto traz parte das idéias apresentadas na dissertação de mestrado da autora, orientada pela profa. dra.Cecilia Hanna Mate (FEUSP) e defendida em 2004: MESOMO, Aliandra C. Educação Infantil: indagando sobre práticas escolarizantes. 2004. 107 f. Dissertação (Mestrado em Educação) - Faculdade de Educação, Universidade de São Paulo.

2. Com a Lei de Diretrizes e Bases da Educação (9394/96), as práticas passaram a constituir-se por dois níveis de atendimento: em creches, para crianças de zero a três anos, e, em pré-escolas, para crianças de quatro a seis anos.

3. Termo usado por Michel Foucault (1987).

4. As Emeis da cidade de São Paulo atendem crianças em três turnos, sendo que, em cada turno, há pelo menos uma turma de cada estágio $-1^{\circ}, 2^{\circ}$ e $3^{\circ}$. As crianças são separadas por idades nos estágios.

5. Considerando-se o número reduzido de páginas deste artigo optamos por não apresentar as fotos analisadas na dissertação. Elas podem ser consultadas no trabalho completo anteriormente refererido.

6. Sobre a diferenciação entre rotina e cotidiano, acompanhar conceitualização da autora (p. 95).

\section{REFERÊNCIAS}

ALVES, N. Decifrando o pergaminho - o cotidiano das escolas nas lógicas das redes cotidianas. In: OLIVEIRA, Inês B. de e ALVES, N. (Org.). Pesquisa no/do cotidiano das escolas - sobre redes de saberes. Rio de Janeiro: DP\&A, 2002.

ARIÈS, P. História social da criança e da família. Rio de Janeiro: LTC Editora, 1981.

BARBOSA, M. C. S. Fragmentos sobre a rotinização da infância. Revista Educação \& Realidade, v. 25, n. 1, p. 93-113, jan./jun. 2000. 
BUJES, M. I. E. Infância e maquinarias. Rio de Janeiro: DP\&A, 2002a.

. Descaminhos. In: COSTA, Marisa V. (Org.). Caminhos investigativos II: outros modos de pensar e fazer pesquisa em educação. Rio de Janeiro: DP\&A, 2002.

. O fio e a trama: as crianças nas malhas do poder. Revista Educação \& Realidade, v. 25, n. 1, p. 25-44, jan./jun. 2000a.

CORAZZA, S. M. Infância \& educação - Era uma vez... Quer que conte outra vez? Petrópolis, RJ: Vozes, 2002.

FISCHER, R. M. B. Foucault e o desejável conhecimento do sujeito. Revista Educação \& Realidade, v. 24, n. 1, p. 39-59, jan./jun. 1999.

FONSECA, M. A. da. Michel Foucault e a constituição do sujeito. São Paulo: Educ, 2003.

FOUCAULT, M. Microfisica do poder. São Paulo: Graal, 2003.

. O sujeito e o poder. In: DREYFUS, H.; RABINOW, P. Michel Foucault. Uma trajetória filosófica. Rio de Janeiro: Forense Universitária,1995.

. Vigiar e punir. Petrópolis: Vozes, 1987.

KISHIMOTO, T. M. Brinquedos e materiais pedagógicos nas escolas infantis. Revista Educação e Pesquisa, v. 27, p. 229-245, jul./dez., 2001.

. Escolarização e brincadeira na educação Infantil. In: SOUZA, C. P. de. História da educação: processos, práticas e saberes. São Paulo: Escrituras, 1998.

KOHAN, W. O. Infância. Entre educação e filosofia. Belo Horizonte: Autêntica, 2003.

LARROSA, J. Tecnologias do eu e educação. In: SILVA, T. T. da (Org.). $O$ sujeito da educação: estudos foucaultianos. Petrópolis: Vozes, 2002.

MATE, C. H. Tempos modernos na escola: os anos 30 e a racionalização da educação brasileira. Bauru: EDUSC; Brasília: INEP, 2002.

NARODOWSKI, M. Infância e poder: a conformação da pedagogia moderna. Bragança Paulista, SP: Editora da Universidade São Francisco, 2001.

; VAN DER HORST, C. Orden y disciplina son el alma de la escuela. Revista Educação \& Realidade, v. 24, n. 1, p. 91-113, jan./jun. 1999.

POPKEWITZ, T. S. História do currículo, regulação social e poder. In: SILVA, T. T. da (Org.). O sujeito da educação: estudos foucaultianos. Petrópolis, RJ: Vozes, 2002.

. Reforma educacional e construtivismo: o estado como uma problemática de governo. In: SILVA, T. T. da (Org.). Liberdades reguladas. A pedagogia construtivista e outras formas de governo do eu. Petrópolis: Vozes, 1998. 
ROCHA, C. M. F. Entre palavras e coisas... infinitos controles. Revista Educação \& Realidade, v. 25, n. 1, p. 183-201, jan./jun. 2000.

ROSE, N. Como se deve fazer a história do eu? Revista Educação \& Realidade, v. 26, n. 1, p. 33-57, jan./jul. 2001.

SILVA, T. T. da. As pedagogias psi e o governo do eu nos regimes neoliberais. In: . (Org.). Liberdades reguladas. A pedagogia construtivista e outras formas de governo do eu. Petrópolis, RJ: Vozes, 1998.

SINGER, H. República de crianças: sobre experiências escolares de resistência. São Paulo: Hucitec, 1997.

VARELA, J. Categorias espaço-temporais e socialização escolar. Do individualismo ao narcisismo. In: COSTA, M. V. (Org.). A escola básica na virada do século: cultura, política e educação. São Paulo: Cortez, 1996.

VARELA, J.; ALVAREZ-URÍA, F. A maquinaria escolar. Revista Teoria \& Educação, n. 6, 1992.

VEIGA-NETO, A. Cultura, culturas e educação. Revista Brasileira de Educação, n. 23, p. 5-15, maio/jun./jul./ago. 2003. 